\title{
Study Outcome Measure Primary Indicator
}

National Cancer Institute

\section{Source}

National Cancer Institute. Study Outcome Measure Primary Indicator. NCI Thesaurus.

Code C94093.

Specifies whether this is the main or principal study outcome measure. 